\title{
Humanity Governance at local level: A case in Insurance Program for Tappers in Indonesia
}

\author{
Denok Kurniasih \\ Universitas Jenderal Soedirman \\ Purwokerto, Indonesia \\ denokkurniasih@yahoo.com
}

\begin{abstract}
Local potency development becomes a substantial aspect to improving local competitiveness. Indonesia leading sector commodity is palm sugar. Its production depends on worker productivity known as penderes or tappers (a man who take coconut water for making a palm sugar). Their job has a high risk, so that they need financial aid. The local government (Banyumas) has launched Insurance Program for tappers to respond it. This article discusses about the implementation of insurance programs for tappers in human governance perspective, which includes social accountability, ethics and moral principles. Besides that there were two determinant factors to reach humanity governance; they are about regulation and budget constraints.
\end{abstract}

Keywords- ethics; humanity governance; insurance program; social accountability.

\section{INTRODUCTION}

Studies on aspects of humanity in the public administration continue to progress. In the initial appearance, humanism approach is used to study about public personnel in the organizational context. Along with the development on focus of administrative science, the humanism paradigm was developed to address the problems that occur in the community. The theorists of organization and administration realize that human problems cannot only be seen from the structure aspect within the organization. They started studying on human relations, culture, ethics and social equity [1], [2], [3], [4], [5].

There have been many problems in society that demands sensitivity of government at the local level. Resolving the poverty problems, the lack of public access to public services, crime, and disability cannot be realized when the government has not put the values of humanity as the basis for the making and implementation of policies. Therefore, humanity governance must be manifested in a variety of programs and activities of government. One of the innovative programs initiated by Banyumas is an insurance program for tappers. The typology of tappers is poor people who work with high risk of accidents. The high risk of their work leads to the emergence of the need for financing guarantees for workplace accidents. The insurance program for tappers aimed to help them in terms of financing for workplace accidents. By the existence of this program, it is expected to help tappers when work accident happens. It shows that the Local Government has a strong commitment to protect the public from the problems of workplace accidents. In other words, local governance have practiced the concept of humanity governance.

Humanity governance within the context of insurance program for tappers is a new culture in local governance. The new culture is emerging in the humanitarian spirit of the local government when they completed a public affairs. Banyumas realized that the tapper's issue can not be solved simply by providing social welfare improvement programs in the same context as other. The tappers require affirmative action because they have a safety problem. Tappers is a non-formal sector workers have no guarantee of security as the formal sector workers. Therefore creating an insurance program for tappers is an attempt to respond public demands in resolving tappers problem. Thus, the government at the local level have attempted to meet the principle of social accountability and moral-ethics as humanity governance characteristics.

\section{METHOD}

This research seeks to answer the question of how the implementation of the insurance program for tappers in the perspective of human governance based on social accountability, ethics and morals principles and what factors that support the implementation of the humanity governance. The research method uses qualitative descriptive. This method is used in exploring and understanding the meaning from some of individuals or groups of people about social and humanities problems [6]. The informant of this research covered the bureaucrats and tappers in Banyumas. The analysis method used interactive analysis model [7].

\section{RESULT AND DISCUSSIONS}

The concept of humanity in public administration is focused more on aspects of human resources in the context of a formal organization [2], [1]. This means that the concept of humanity is used to see human as a public organization asset that must be managed properly. However, the view that the public administration is an organism that is possible to have human nature began to be widely studied today. With the growing focus on public administration, the study on human values such as ethics and morality is begun [2], [8], [4], [5]. 
The attention to the humanitarian aspect leads to obtaining recognition that human is important. Humanity in public administration should be oriented on respect for human beings. It also focuses on what kind of people we become in administration, not just how tasks are carried out and organisation goals are formally fulfilled, but how cognizant one is of the moral dimensions of one's work, effects on personality and character, as well as the consequences for one's personal life. The goal of humanism is selfunderstanding and a unification of the moral, aesthetic and spiritual, rather than the compartmentalization that the bureaucratic or technocratic imposes, including the right to resist and the right to civil disobedience [2].

The emergence of humanity concept becomes an important moment in the governance implementation at the local level. The local community is in need of a government that has sensitivity to their problems. A sensitive, empathetic, sympathetic and responsive government is needed to overcome poverty. The government should also ensure the safety rights of all communities, including the community of tappers. Humanist government may have sensitivity to the problems of humanity (inadequacy and powerlessness) that occur in the community.

Humanity governance is a new culture in the public administration practices. The concept of governance itself has a broad perspective. However, this paper represents the overall governance qualities of the relationship between citizens (both private and public) and the government that contains the values of responsiveness, efficiency, honesty and fairness [3]. Thus, humanity governance is an idea about a new culture in managing the relationship between the citizens and the government which emphasizes the aspects of humanity. According to [9] human governance is a cultural model managing the relations between the state and the individual as citizens who have the freedom to choose, freedom to have different voice, dignity, and the right to be treated by the government or the state (social accountability principle). In other words, human governance is an effort to make the humanity government or public administration or a culture to re-humanize governmental administration. By using the theoretical of human governance, this paper focus on the principles of human governance as below :

\section{A. Social Accountability}

Public accountability is the hallmark of modern democratic governance [10]. Accountability refers to a mechanism given to public officials to be able to explain and make sure that they had acted properly, behave ethically, and are responsible for their performance [10], [11], [12], [13]. Therefore, accountability is also related to the effort to establish the legitimacy of a government.

This paper discusses on social accountability, where the use of the word "social" is related to "relation". Accountability can be defined as a social relationship in which an actor feels an obligation to explain and to justify his or her conduct to some significant other [14], [15], [16], [17]. Thus, social accountability is a form of government accountability to the public in terms of satisfying the demands of society as a consequence of social relationship.

In the era of government, the government plays an important role in controlling society. While the paradigm of governance, there are many interest groups directly involved in the formulation and implementation of public policy [18], [19]. The concept of governance takes into account all the actors and policy areas which are outside the "core executive" involved in policy-making [20]. It shows that the concept of governance may have implications for the demands of social accountability. The government must be ensured to have carried out the principles of social accountability in the form of appreciation for the relationship built with the community. It is characterized by the dialogue between the community groups voicing their aspirations to the government [10].

Insurance program for tappers is an effort of the local government in realizing social accountability. The tappers are group of people who work in the non-formal sector. Their condition is so poor so that they have many limitations. On the other hand, the tappers have an important role in supporting program to increase regional competitiveness by supplying the raw material for palm sugar. Palm sugar is a mainstay local commodity in Banyumas. Currently, the potential development of palm sugar becomes an important program in supporting the regional competitiveness. Therefore, insurance program of tappers is a response to the needs of safety guarantees demanded by tappers community.

The issue faced by tappers has long become an important issue in Banyumas. Through various dialogue forums between the government and the group of tappers, social activists, legislators and academics, this issue is then responded by the government through the emergence of insurance program for tappers. This program is motivated by the increase in the number of accidents experienced by tappers from year to year. In addition, the local government is also aware that the tappers have an important role in the production palm sugar as superior product in Indonesia. The government recognizes that safety is the right of every citizen, not just a commodity [1] which supports the competitiveness of the region.

The involvement of the actors is very important in realizing the insurance program for tapper. The local government provides the facilities in terms of dialogue between the various stakeholders, including the tappers, assistance team from NGOs and other social activists. The dialogue is based on the aim of overcoming the problems. The implementation of insurance policy shows the success of the dialogue process conducted by the government and stakeholders. This success is due to their openness and sincerity to understand each other. As described by [21], the success of an authentic dialogue is based on four basic conditions, namely (1) integrity, (2) accuracy, (3) comprehensibility, and (4) legitimacy. The government had promised that the tappers are the priority in regional development policy. During the campaign of regent and deputy regent, the tappers become a political jargon that 
has won them. The existence of this program shows that the local government has tried to fulfill his promise.

The insurance program for tappers appears as a result of instigation of the actors within the scope of tappers issue. According to [22], three 'streams' must be aligned for a matter to be dealt with in the public policy arena: the problem stream (is the condition considered a problem?), the policy stream (are there are policy alternatives that can be implemented?), and the political stream (are politicians willing and able to make a policy change?). When these three streams come together, a window of opportunity is open and action can be taken on the subject at hand. In this case, tappers group and social activists as well as media have an important role in supporting the implementation of this program. The government who are open to the mechanism public dialogue may have a lot of information to take out a policy. The openness of government and the existence of these dialogue forums are the characteristic of social accountability process. As stated by [10] that public accountability requires openness or at least wase of access for citizens, in this case is the ease of getting information on government performance.

\section{B. Ethics and Morality in Humanity Governance}

Human governance is a new culture in public administration. Through this concept, the practices of public administration can be more humane [9]. One of the important principles in human governance is related to ethics and morals. There are many studies on ethics and moral in the sphere of public administration [3], [24], [25]. Ethics and morals become one of the most important dimensions in public administration because of the activities of public administration is related to certain public purposes and objectives, directed to satisfy the public interest or happiness, and run with the obligation and the right motives [26]. As also described by [27], in realizing accountability, the government actually faces three main points, namely the effectiveness, fairness and ethics. Effectiveness relates to the achievement of the objectives of the policy generated, while the policy generated must satisfy the equity of all members of community and most importantly to be in accordance with the role of conduct prevailing in society.

The insurance program for tappers in the perspective of ethics and morals is a form of enjoyment of human rights. The paradigm of human rights has become an important framework in studying the ethical issues [1]. The country should be able to guarantee the health and safety of the citizens because health the right of every citizen. However, realizing those mentioned above is not easy. In fact, there is a saying that says that no government is capable of ensuring the health of every citizen. It has implications for the emergence of a variety of approaches to resolve the issue of public health. Through the insurance program for tappers, the government at the local level at least began to realize that the government should be present at every problem faced by the community. The presence of government is a manifestation of the fulfilment of human rights. Therefore, the effort of Banyumas Regency in fulfilling the rights of their people really needs to be appreciated.

Ethics are linked to moral principles which form the basis for action [24]. Therefore, public policy as a government action certainly needs a base in the form of moral principles. Meanwhile, the reform of decision making at the local level has been linked significantly to the increasing accountability of the local government [28]. This is because the policies generated by the government are an important tool in realizing the public welfare. Therefore, the reform of public policy should be directed to the application of ethical and moral principles in order to realize the public welfare. In the context of local government, the effort is carried out through the creation of local laws that promote ethical and moral values. The local government recognizes that the problem of tappers workplace accidents is a public issue. Referring to the opinion of [29], the definition of public issue in the formulation of policy is an important factor in order to generate quality public policy. This can be seen from how the government defines the problem of tapper workplace accidents so that it appears the understanding on the needs of work safety assurance.

Tappers group is non-formal sector workers recognized by the government to have a difficulty in getting the rights as formal sector workers. Workplace accident insurance can only be given to those who work in the formal sector. This certainly does not apply to the tappers. The Policy of Banyumas Government can be an example for other regions that have a group of people with risky jobs, such as fishermen. At least, this program can help to increase public confidence in the government which has been considered insufficient. It should be understood that the main product of public administration is public policy [30], [31], so as to realize social equity, one of the factors that must be met is the quality of public policy.

The local government has provided affirmative action for the tappers group. This means that the government concerns to the tappers group. Referring to the opinion of [32], the concept of social equity does not encourage any person or group to get the same parts, but how to deliver equity as closely as possible to the people who are less fortunate. Deliberative process is needed when deciding to create this program. The government continue to face the fact that the tappers need help. The increasing number of workplace accidents every year is also a motivating factor to immediately create the policy. The mechanism of dialogue maintained also provides the direction for the concern of the government. Therefore, the government can figure out which group is in need of assistance. It shows that humanity governance requires moral sensitivity and openness. Creating a policy should not only be guided by the rules, but should also strive to realize the moral sensitivity of the actors involved. The value that should be prioritized in the decision making is a moral philosophy centered on man, not an action or rule alone. This important criterion in public policymaking can realize the moral sensitivity of the implementing actors in the process of policy, realize empathy and protect each other [33]. 


\section{Regulations and Budget Constraints as Determinants in Humanity Governance}

Decision making becomes essential for resolving a public problem. Public policy focuses on what [34], said as "public and its problems". Public policy discusses about how issues and problems are formulated and defined, and how all of them are put on the policy agenda and political agenda [35]. In addition, public policy is a study on how, why and what is the effect of active and passive government action [36].

Implementing insurance program for tappers is not something simple. This is due to the policy of providing insurance turns out to have consequences on the budget issue. With the number of tappers reaching 27,300 people, the government will be burdened with budget issues. The tappers who had an accident with permanent disability may receive compensation by Rp. 15 millions, moderate disability by Rp. 5 millions and death by Rp. 10 millions. The funding comes from the allocation of funds for social assistance. Thus, the work accident insurance program is actually still in the form of grants for tappers. However, the government needs to be appreciated because the tappers are group of people who work in the non-formal sector, making it difficult for them to get insurance as in the formal group. With a high occupational risk, the government realized that the tappers require collateral for work accidents. Moreover, the number of tappers who had an accident continues to increase. In 2014, the number of beneficiaries is 138 people and it rose to 142 in 2015. It has reached 95 people up to August, 2016.

In order to facilitate the implementation of the program, the local government has made an innovation by creating tapper card. Through the card, the procedure of applying grants to workplace accidents can be easier and quicker. Nevertheless, it still needs to be confirmed by more specific regulations regarding tappers. Politically, legislative board has also prompted the government to make local regulation that does not only regulate workplace accidents, but also to the empowerment of tappers. In addition, the cooperation with third parties, such as insurance companies and banks is also important.

The implementation of the accident insurance program for tappers provides an overview of the strong commitment of the local government. However, the constraints in the implementation of the program cannot be denied. The most crucial issue is related to the budget. On one hand, the government has the capacity to deliver social equity, but on the other hand, the budget demands efficiency. It shows the phenomenon of trade off between efficiency and social equity values. Without clear and immediate results, it is difficult to build support for programs that are designed to reduce inequity and argue that they are economical, effective, or efficient. In fact, it is most often assumed that there is a trade-off between equity, economy, and efficiency. [37], [38]. In the context of limited resources, the equity versus efficiency trade-off is a major issue when prioritize health care. There is no consensus on how to balance equity with efficiency within the Nasional
Health System, leading [37], to argue that the trade-off has led to "inconsistent judgements in the development of health policy" and to appeal for guidance from the Nasional Health System when equity and efficiency conflict.

To overcome the problem of budgets constraints, the government can involve private sector to provide health insurance with low premises or cost according to the ability of tappers. So far, the public health insurance availability only devoted to health and not for work accident. Work Accident insurance can be obtained if a person is working in a company, and the company is registering its employees to get a work accident insurance. Therefore, the local government create innovation by utilizing social funds to make insurance program for tappers.

The aspect of innovation may be associated with the regulatory aspect. A review of the scholarly literature on the relationship between innovation and regulation suggests that in order for innovation to occur, entrepreneurs must have the willingness, opportunity/motivation, and capability or capacity to innovate, and that regulation can affect all three aspects [39]. Regulation can at times be a powerful stimulus to innovation. Regulation matters at all stages of the innovation process. Different types of regulation can be identified in terms of innovation impact: general or horizontal, innovation specific and sector specific regulation. More prescriptive regulation tends to hamper innovative activity, whereas the more flexible regulation is, the better innovation can be stimulated. Lower compliance and red tape burdens have a positive effect on innovation.

Therefore, the presence of ethics and moral can be a determinant bridge for the government in terms of partisanship. The action of Banyumas government is a discretionary form carried out to address issues that are considered important, [22] referred to as the problem streams. This problem stream found with political stream can open a policy window, so that a policy can be created. Discretion is very important to be carried out concerning ethics and morality. Ethical action in public management plays out in discretion. Public administrative discretion lives at the nexus point of three lines of moral consideration. First, if discretion exists for public managers, the problem of accountability and the link between administration and liberal democracy becomes much more complicated. Second, discretion isolates and highlights the moral responsibility of managers. Finally, framing and managing component, effective, and accountable discretion becomes the focus of ethics policy and institutional design [24]

\section{CONCLUSIONS}

The reform of local government decision making and accountability has been significant. By humanity governance as a basic value of decision making reform, local government can realize social accountability and compliance with ethical and moral aspects of governance. This is because humanity governance can stimulate the sensitivity of the government to 
develop patterns of authentic dialogue and openness. The government and community provide information each other required in the resolution of a problem, so that the policies are consistent with the needs of the community. This accident insurance program for tappers has become an overview that the government is able to answer the demands of society. Humanity governance demands patterns of dialogue and openness between the government, community and other sectors. With humane government, the process of social accountability and the application of ethics and moral values can be run properly. However, based on the result of research, regulatory aspects and budgetary commitment are still the obstacles to humanity governance. The contradiction between efficiency and social equity, then the relationship between innovation policies and regulation are the factors that still need to be considered.

\section{REFERENCES}

[1] W. Austin, "Using the human right paradigm in health ethics: The problems and the possibilities", in Nursing Ethics, vol. 8(3) 2001, pp. 183-195.

[2] E. Samier, "Toward public administration as a humanities discipline": A humanistic manifesto, in Halduskultuur, vol 6, pp. 6-59, 2005.

[3] D. Ferranti, J. Jacinto, A.J. Ody \& Ramshaw, "How to Improve Governance A New Framework for Analysis and Action", Washington D.C : The Bookings Institution, 2009.

[4] Y. Lee, S. Kim, G. Kim, "Ethical Assessment of National Health Insurance System of Korea", Asia-Pasific Journal of Public Health, vol.24 (5), pp.872-879.

[5] C.R. Urbano, "Public administrastion ethics: James Svara's Model", in Journal of human value, vol.20, pp.1-17, 2014

[6] J. Creswell, "Desain Penelitian, Pendekatan Kualitatif dan Kuantitatif" terjemahan Angkatan III \& IV, Jakarta: KIK-UI, KIK Press, 2010.

[7] B. M. Milles, M.A. Huberman \& J. Saldana, "Qualitative Data Analysis, A Methode Sourcebook", USA: Sage Publication. Inc, 2014.

[8] L.I. Saban, "Looking into the eyes of those we serve : Toward complex equality in public administration ethics", in The american review of public administration, vol. 4, pp. 141-156, 2011.

[9] M. Thoha, "Ilmu Administrasi Publik Kontemporer". Jakarta: Kencana, 2008.

[10] M. Bovens, Public Accountability, The Oxford Handbook of Public Management, New York: Oxford, 2005.

[11] M.J. Dubnick, "Accountability and ethics: Reconsidering the relationships", in International journal of organization theory and behavior. vol. 6 (3), pp. $405-441,2003$

[12] Mulgan, "Accountability: An ever-expanding concept ?", in Public administration review, vol. 78, 2003.

[13] B. Romzek \& P.W. Ingraham, "Cross pressure of accountability: initiative, command, and failure in the ron brown plane crash", in Public administration review, vol. 60, pp. 240 - 251, 2000.

[14] P. Day \& R. Klein, "Accountabilities: Five Public Services", London: Tavistock, 1987.

[15] J.S. Lerner \& P.E. Tetlock, "Accounting for the effects of accountability", in Psichological bulletin, vol. 125, pp. 255-275, 1999.

[16] H.E. McCandless, "A Citizen's Guide to Public Accountability: Changing the Relationship Between Citizens and Authorities", Victoria, BC: Trafford, 2001.

[17] C. Pollit, "The Essential Public Manager", London: Open University Press/McGraw-Hill, 2003

[18] N. Nelisen, "The administrative capacity of new types of governance", in Public organization review, vol. 2, pp.23-43, 2002.

[19] V. Chhotray \& G. Stoker, "Governance Theory and Practice: A crossDisciplinary Approach”, New York: Palgrave Macmillan, 2009.
[20] D. Richard \& M.J. Smith, "Governance and Public Policy in the UK", Oxford: Oxford University Press, 2002

[21] D.E. Booher \& J.E. Innes, "Network power in collaborative planning", in Journal of planning education and research, vol. 21(3), pp.221-236, 2002.

[22] J. Kingdon, "Agendas, Alternatives, and Public Politics", 2nd ed, New York: Harper Collins, 1995.

[23] K. Bartens, Pengantar Etika Bisnis, Yogyakarta: Kanisius, 2000.

[24] P. Dobel, "Public Management as Ethics, The Oxford Handbook of Public Management", New York: Oxford, 2005.

[25] Lewis \& Gilman, "The Ethics Challenge in Public Service, A ProblemSolving Guide", San Fransisco: Jossey-Bass, 2005

[26] Y. T. Keban,"Enam Dimensi Strategis Administrasi Publik", Yogyakarta Gava Media, 2008

[27] W. Cameron, "Public accountability: efectiveness, equity and ethics", in Australian journal of public administration, vol. 63 (4), pp.59-67, 2004.

[28] J. Morphet, "Modern Local Government", New York: Sage Publication, 2008.

[29] W.N. Dunn, "Public Policy Analisys: An Introduction", 4th ed. New Jersey: Pearson, Prentice-Hall, 2008.

[30] S.P. Naidu, "Public Administration: Concepts and Theories", New Delhi New Age International Ltd, 2005.

[31] K.B. Smith \& C.W. Larimer, "The Public Policy Theory Primer", Boulder: Westview Press, 2009.

[32] J. Rawls, "A Theory of Justice", Cambridge, MA, Belknap Press, 1971.

[33] D. Ticu, "Public policies-from the dilemma of resources allocation to the ethical decision making", in The young economists journal, 2008.

[34] J. Dewey, "The Public and Its Problems", Denver: Swallow Press, 1927.

[35] W. Parson, "Public Policy: An Introduction to the Theory and Practice of Policy Analysis", Edward Elgar Publishing, Ltd, 2005.

[36] A. Heidenheimer, H. Hecto \& C.T. Adam, "Comparative Public Policy: The Politics of Social Choice in America, Europe, and Japan", New York: St.Martin Press, 1990

[37] F. Sassi, J. Le Grand, L. Archard, "Equity versus efficiency: a dilemma for the NHS". in BMJ, vol. 323, pp. 762-763, 2001

[38] K. Norman, "Balancing the four ES ; or Can we achieve equity for social Equity in public administration?", in Journal of public affairs education, vol. 17, pp. 233-252, 2011

[39] J. Pelkmans \& A. Renda, "Does EU regulation hinder or rtimulate innovation ?", in Center for european policy studies, vol. 96, pp 1-38, 2014 
